\title{
Sistem Instrumentasi Pada Pendeteksian Tangan dan Monitoring Tangki Persediaan Alat Cuci Tangan Otomatis Menggunakan Photovoltaic
}

\section{Instrumentation System on Hand Detection and Tank Monitoring Auto Wash Supplies Using Photovoltaic}

\author{
Anggia Bunga Pertiwi Kakiay ${ }^{1}$, Dian Budhi Santoso ${ }^{2}$, Ulinnuha Latifa ${ }^{3}$ \\ ${ }^{123}$ Universitas Singaperbanga Karawang \\ 1 $\underline{\text { anggia.bunga16028@ student.unika.ac.id, }}{ }^{2}$ dian.budhi@ft.unsika.ac.id, ${ }^{3} \underline{\text { ulin.ft.unsika@gmail.com }}$
}

\begin{abstract}
Abstrak
Perilaku Hidup Bersih dan Sehat (PHBS) adalah semua perilaku kesehatan yang dilakukan atas kesadaran dan penerapan PHBS ini dapat dimulai dari hal yang sangat sederhana namum memiliki dampak yang besar misalanya Cuci Tangan Menggunakan Sabun atau CTPS. Cuci tangan yang dipraktikan secara benar dan tepat merupakan cara yang termudah dan sangat efektif untuk mencegah berbagai macam penyakit. Alat ini menggunakan mikrokontroler arduino, sensor infrared yang digunakan untuk mendeteksi tangan, sensor ultrasonik sebagai pendeteksi pada tangki dan LCD I2C sebagai interface. Sensor proximity yang digunakan ini mampu mendeteksi tangan dari jarak 3-12 cm. Sedangkan sensor ultrasonik mampu mendeteksi persedaiaan didalam tangki dengan keakurasian permbacaan sensor dengan nilai aktual sebear 99,68\% untuk tangki air dan 99,61\% untuk tangki sabun. LCD I2C 16x2 mampu menampilkan level monitoring dalam bentuk persentase $0-100 \%$.
\end{abstract}

Kata kunci : arduino, sensor infrared, sensor ultrasonik, intrumentasi

\section{Abstract}

Clean and Healthy Living Behavior is all health behaviors carried out on the awareness and application of PHBS can start from a very simple thing namum has a great impact e.g. Hand Washing Using Soap. Properly practiced hand washing is the easiest and most effective way to prevent a wide range of diseases. It uses an arduino microcontroller, an infrared sensor used to detect hands, an ultrasonic sensor as a detector on a tank and an I2C LCD as an interface. This proximity sensor is capable of detecting hands from a distance of 3-12 cm. While ultrasonic sensors are able to detect the in-tank in-tank with sensor readability with actual values of $99.68 \%$ for water tanks and $99.61 \%$ for soap tanks. I2C 16x2 LCD is capable of displaying monitoring level in the form of 0-100\% percentage.

Key words: arduino, infrared sensor, ultrasonic sensor, intrumentation

\section{PENDAHULUAN}

Perilaku Hidup Bersih dan Sehat (PHBS) adalah semua perilaku kesehatan yang dilakukan atas kesadaran, sehingga anggota keluarga atau keluarga dapat menolong dirinya sendiri di bidang kesehatan dan berperan aktif dalam kegiatan-kegiatan kesehatan di masyarakat. Penerapan PHBS ini dapat dimulai dari hal yang sangat sederhana namum memiliki dampak yang besar misalanya Cuci Tangan Menggunakan Sabun atau CTPS [1]. Cuci tangan yang dipraktikan secara benar dan tepat merupakan cara yang termudah dan sangat efektif untuk mencegah berbagai macam penyakit. Salah satu mikroorganisme penyebab penyakit yang mematikan adalah Corona Virus Disease atau COVID-19 yang telah ditetapkan oleh WHO sebagai Pandemi pada awal tahun 2020, yang 
berdampak adanya perubahan tatanan kehidupan yaitu new normal [2]. Adapun protokol yang dimaksud dalam pelaksanaan new normal ini adalah tetap mengedepankan protokol kesehatan dimapun kita berada yang salah satunya adalah menjaga tangan kita agar tetap bersih [3].

Pada penelitan terdahulu yang dilakukan oleh Hendry Santoso tahun 2008 tentang alat serupa menceritakan tentang pembuatan mesin cuci tangan otomatis menggunakan sensor optokopler sebagai input komparator dan keluaran yang dihasilkan berupa timer waktu kerja pompa selama 5 detik dengan error sebesar 10\% [4]. Selanjutnya penelitan serupa juga dilakukan oleh Hafizur Rizki dan Wildan pada tahun 2015 dengan sensro fotodioda yang memiliki respon cepat terhadap perubahan cahaya namun pada perancangannya alat ini tidak memiliki tangki berkapasitas besar untuk persediaan sabun dan level moitorng dari persediaan sabun[5].

Untuk mengatasi beberapa kelemahan terebut maka dilakukan penelitian mengenai sistem intrumentasi pada alat cuci tangan otomatis menggunakan photovoltaic yang memiliki 2 tangki persediaan yaitu tangki ait dan tangki sabun dengan tujuan memaksimalkan kerja sensor yang digunakan. Mikrokontroler Arduino merupakan pengendali input dan output pada alat ini. Input dari alat ini merupakan sensor infrared yang mendeteksi adanya objek yaitu tangan dan dua sensor ultrasonik sebagai pendeteksian persediaan pada kedua tangki sehingga output yang dihailkan berupa tampilan dapa layar LCD yang berupa persentase persediaan pada kedua tangki.

\section{METODOLOGI}

Metode penelitian yang digunakan kali adalah penelitian dan pengembangan atau Research and Development $(\mathrm{RnD})$ yang merupakan suatu proses atau langkah-langkah untuk mengembangkan suatu produk baru atau menyempurnakan produk yang telah ada dan dapat dipertanggungjawabkan. Berikut ini merupakan percancagnan perangkat lunak sistem secara keseluruhan:

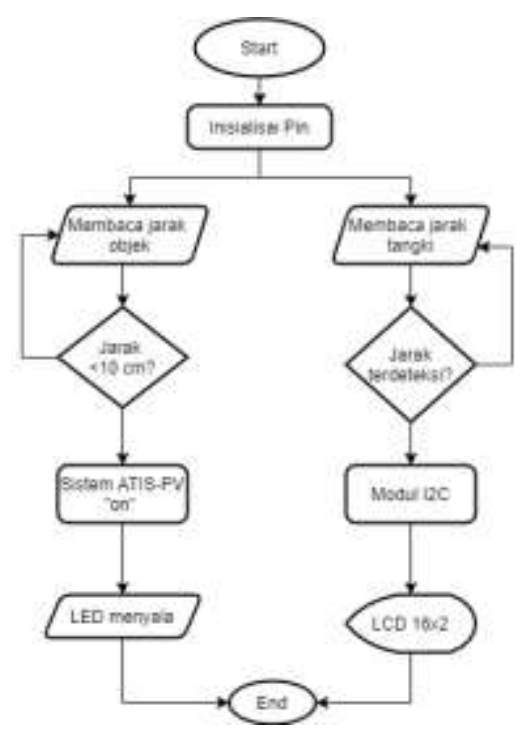

Gambar 1 Blok Diagram Peneliatian

Pada Gambar 1 Sensor proximity ini digunakan sebagai pendeteksian objek dan ultrasonik sebagai pendeteksian kedua tangki. Untuk mengetahui seberapa akuratnya kinerja dari sensor yang digunakan maka dilakukan pengujian sistem instrumentasi yaitu pengujian karakteristik dari modul sensor dan interface. Adapun beberapa pengujian yang dilakukan yaitu mengetahui fungsi transfer, linieritas, sensitifitas, dan akurasi. 


\subsection{Perancangan Sistem}

Desain perancangan perangkat keras dari alat yang akan dibuat adalah berdasarkan hasil studi literatur dan uji coba alat pada bagian sebelumnya. Berikut adalah desain perancangan perangkat keras alat:

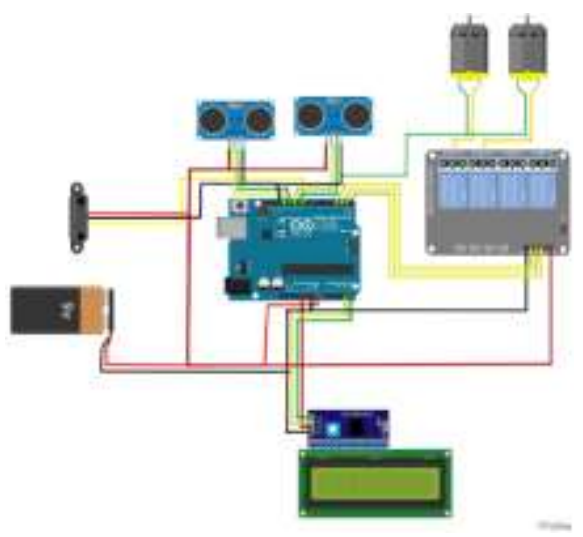

Gambar 2 Desain Perangkat Keras

\section{HASIL DAN PEMBAHASAN}

Hasil pembahasan perancangan instrumen pada ATIS-PV ini terdiri dari, modul sensor dan antarmuka LCD. Adapun modul sensor yang dimaksud adalah sensor proximity dan dua sensor ultrsaonik.

\subsection{Hasil Pengujian Sensor Proximity}

Sensor E18-D80NK pada penelitian ini digunakan untuk memulai proes kerja alat yang dilakukan dengan cara mendekatkan tangan kearah sensor dengan range yang telah ditentukan. Dari spesifikasi yang ada disebutkan bahwa sensor ini memiliki range 3-80 cm, maka dari itu pengjuan ini dilakukan dengan cara mengamati nilai tegangan keluaran sensor infrared pada multimeter baik pada kondisi objek terdeteksi maupun tidak dengan 20 kali percobaan dirange pendeteksian 3-22 $\mathrm{cm}$. Berikut ini merupakan tabel pengujian tegangan sensor proximity.

Tabel 1 Data Hasil Pengujian Sensor Proximity

\begin{tabular}{|l|c|c|c|c|c|}
\hline No & $\begin{array}{c}\text { Jarak Objek } \\
(\mathbf{c m})\end{array}$ & $\begin{array}{c}\text { Tegangan } \\
(\mathbf{v o l t})\end{array}$ & Masukan & $\begin{array}{c}\text { Lampu } \\
\text { Indikator }\end{array}$ & $\begin{array}{c}\text { Kondisi } \\
\text { Pembacaan }\end{array}$ \\
\hline & & & & & \\
\hline $\mathbf{1 .}$ & 3 & 4,83 & Low & On & Tangan Terdeteki \\
\hline $\mathbf{2 .}$ & 4 & 4.83 & Low & On & Tangan Terdeteki \\
\hline $\mathbf{3 .}$ & 5 & 4,83 & Low & On & Tangan Terdeteki \\
\hline $\mathbf{4 .}$ & 6 & 4,83 & Low & On & Tangan Terdeteki \\
\hline $\mathbf{5 .}$ & 7 & 4,83 & Low & On & Tangan Terdeteki \\
\hline 6. & 8 & 4,83 & Low & On & Tangan Terdeteki \\
\hline $\mathbf{7 .}$ & 9 & 4,83 & Low & On & Tangan Terdeteki \\
\hline $\mathbf{8 .}$ & 10 & 4,83 & Low & On & Tangan Terdeteki \\
\hline $\mathbf{9 .}$ & 11 & 4,83 & Low & On & Tangan Terdeteki \\
\hline $\mathbf{1 0}$ & 12 & 4,83 & Low & On & Tangan Terdeteki \\
\hline
\end{tabular}


JEC Vol. 6 No. 2

Jurnal Electro Luceat [November $][2020]$

\begin{tabular}{|l|l|l|l|l|l|}
\hline 11. & 13 & 0 & High & Off & Tidak Terdeteksi \\
\hline 12. & 14 & 0 & High & Off & Tidak Terdeteksi \\
\hline 13. & 15 & 0 & High & Off & Tidak Terdeteksi \\
\hline 14. & 16 & 0 & High & Off & Tidak Terdeteksi \\
\hline 15. & 17 & 0 & High & Off & Tidak Terdeteksi \\
\hline 16. & 18 & 0 & High & Off & Tidak Terdeteksi \\
\hline 17. & 19 & 0 & High & Off & Tidak Terdeteksi \\
\hline 18. & 20 & 0 & High & Off & Tidak Terdeteksi \\
\hline 19. & 21 & 0 & High & Off & Tidak Terdeteksi \\
\hline 20. & 22 & 0 & High & Off & Tidak Terdeteksi \\
\hline
\end{tabular}

Dari hasil pengujian dapat disimpulakan bahwa sensor ini berkeja dengan memanfaatkan diode cahaya pada saat sensor ini mendapat sinyal masukan "low" maka sensor ini akan memberikan sinyal untuk menghidupkan sistem dan jika sensor ini mendapat inpputan "high" maka sebaliknya. Sensor ini hanya akan mendeteksi dua kondisi yaitu ketika adanya objek berupa tangan dan tidak. Berdasarkan hasil pengujian senor ini mampu mendeteksi tangan pada jarak 3-12 cm.

\subsection{Hasil Pengujian Sensor Ultrasonik}

Pengujian sensor ultrasonik ini bertujuan untuk menganalisa karakteristik sistem kerja sensor ultrasonik HC-SR04 dalam mendeteksi volume didalam tangki persediaan. Pengujian ini dilakukan dengan cara menghubungkan sensor ultrasonik ke sistem Arduino sebgai berikut:

- Vcc sensor ultrasonic pada Vcc 5 V Dc Arduino

- Echo sensor ultrasonic pada pin 12 dan 9 arduino

- Trig sensor ultrasonic pada pin 13 dan 10 arduino

- Gnd sensor ulreasonik pada GND Arduino

Sensor ultrasonik ini adalah sensor yang dapat mengukur jarak dari $2 \mathrm{~cm}-300 \mathrm{~cm}$. Sensor ini menerima tegangan input sampai 5 V DC. Berikut ini merupakan tabel hasail pengujian kedua sensor ultrasonik.

Tabel 2 Pengujian Sensor Ultrasonik Air

\begin{tabular}{|c|c|c|c|c|}
\hline \multirow{2}{*}{ No } & \multirow{2}{*}{$\begin{array}{c}\text { Jarak } \\
(\mathbf{c m})\end{array}$} & \multicolumn{3}{|c|}{ Pulsa Echo $(\boldsymbol{\mu S})$} \\
\cline { 3 - 5 } & & $\begin{array}{c}\text { Pengujian } \\
\mathbf{1}\end{array}$ & $\begin{array}{c}\text { Pengujian } \\
\mathbf{2}\end{array}$ & $\begin{array}{c}\text { Pengujian } \\
\mathbf{3}\end{array}$ \\
\hline 1 & 2 & 138 & 162 & 118 \\
\hline 2 & 4 & 286 & 254 & 246 \\
\hline 3 & 6 & 359 & 341 & 367 \\
\hline 4 & 8 & 484 & 460 & 464 \\
\hline 5 & 10 & 621 & 641 & 646 \\
\hline 6 & 12 & 716 & 723 & 736 \\
\hline 7 & 14 & 813 & 858 & 827 \\
\hline 8 & 16 & 960 & 981 & 839 \\
\hline 9 & 18 & 1115 & 1062 & 1080 \\
\hline 10 & 20 & 1212 & 1204 & 1180 \\
\hline
\end{tabular}


JEC Vol. 6 No. 2

Jurnal Electro Luceat [November $][2020]$

Tabel 3 Pengujian Sensor Ultrasonik Sabun

\begin{tabular}{|c|c|c|c|c|}
\hline \multirow{2}{*}{ No } & \multirow{2}{*}{$\begin{array}{l}\text { Jarak } \\
(\mathbf{c m})\end{array}$} & \multicolumn{3}{|c|}{ Pulsa Echo $(\boldsymbol{\mu S})$} \\
\cline { 3 - 5 } & & $\begin{array}{c}\text { Pengujian } \\
\mathbf{1}\end{array}$ & $\begin{array}{c}\text { Pengujian } \\
\mathbf{2}\end{array}$ & $\begin{array}{c}\text { Pengujian } \\
\mathbf{3}\end{array}$ \\
\hline $\mathbf{1}$ & 2 & 162 & 135 & 159 \\
\hline $\mathbf{2}$ & 4 & 250 & 288 & 249 \\
\hline $\mathbf{3}$ & 6 & 411 & 405 & 405 \\
\hline $\mathbf{4}$ & 8 & 476 & 519 & 515 \\
\hline $\mathbf{5}$ & 10 & 616 & 630 & 610 \\
\hline $\mathbf{6}$ & 12 & 774 & 779 & 721 \\
\hline $\mathbf{7}$ & 14 & 827 & 826 & 830 \\
\hline $\mathbf{8}$ & 16 & 951 & 964 & 973 \\
\hline $\mathbf{9}$ & 18 & 1085 & 1079 & 1121 \\
\hline $\mathbf{1 0}$ & 20 & 1215 & 1218 & 1208 \\
\hline
\end{tabular}

Berdasarkan pada Tabel 2 dan Tabel 3 maka grafik linieritas yang didapatkan adalah sebagai berikut:

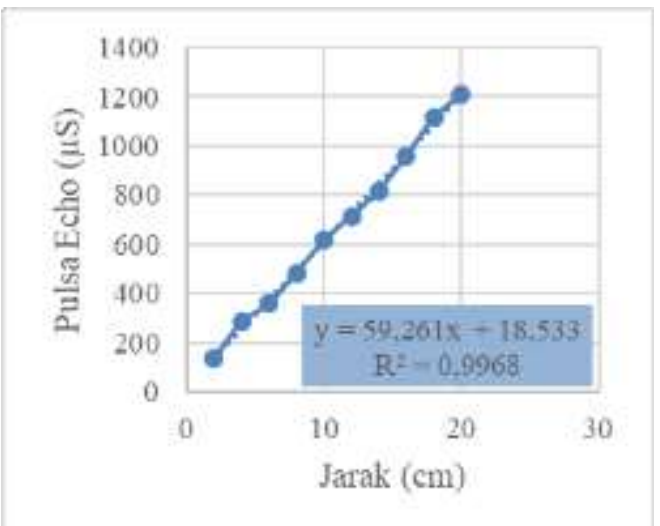

Gambar 4 Grafik Linieritas pada tangki air

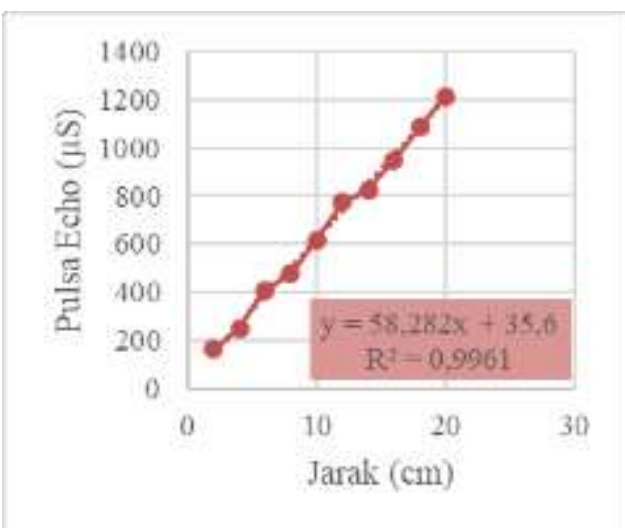

Gambar 5 Grafik Linieritas pada tangki sabun

Sensor ini mendapatkan inputan berupa jarak antara sensor dengan permukaan cairan di dalam tangki dan Gambar 4 dan Gambar 5 merupakan kemampuan sensor untuk membentuk hubungan antara input dan output yang diwujudkan melalui persamaan garis lurus, yang dimana sumbu X merupakan jarak input dan $\mathrm{cm}$ dan sumbu Y merpakan output echo dalam satuan waktu yang dihasilkan dari pembacaan senor. Nilai sensitivitas dari senor ini dinyatakan dari nilai slope grafik yang ada pada tiap pengujian sensor yaitu 59,261 $\mu \mathrm{S} / \mathrm{cm}$ untuk sensor air dan 58,282 $\mu \mathrm{S} / \mathrm{cm}$ 
untuk sabun, hal ini menujukan bahwa dalam setiap kenaikan $1 \mathrm{~cm}$ maka hasil pembacaan sensor akan mengalami kenaikan sesusai dengan nilai sensitifitas yang didapat. Selain nilai sesitivitas nilai akurasi pada perhitungan sensor dapat dilihat pada slope grafik yang diperoleh dimana pada perhitungannya hasil dari slope pada grafik dikalikan dengan $100 \%$ dan menghasilkan nilai akurasi sebesar $99,68 \%$ dan $99,61 \%$.

\subsection{Hasil Pengujian LCD I2C}

Pengujian LCD ini dilakukan dengan cara melihat tampilan LCD apakah menyala atau tidak dan melihat tampilan interface LCD apakah sesuai dengan kapasita air atau tidak. Berikut merupakan table perngujian dari LCD:

Tabel 4 Pengujian LCD untuk tangki air

\begin{tabular}{|l|l|l|}
\hline No & $\begin{array}{l}\text { Level Air } \\
\text { (cm) }\end{array}$ & $\begin{array}{l}\text { Tampilan } \\
\text { LCD }\end{array}$ \\
\hline 1 & $<10$ & $20 \%$ \\
\hline 2 & $>11<20$ & $40 \%$ \\
\hline 3 & $>21<30$ & $60 \%$ \\
\hline 4 & $>31<40$ & $80 \%$ \\
\hline 5 & $>41<50$ & $100 \%$ \\
\hline
\end{tabular}

Tabel 5 Pengujian LCD untuk tangki sabun

\begin{tabular}{|l|l|l|}
\hline No & $\begin{array}{l}\text { Level Air } \\
\text { (cm) }\end{array}$ & $\begin{array}{l}\text { Tampilan } \\
\text { LCD }\end{array}$ \\
\hline 1 & $<5$ & $20 \%$ \\
\hline 2 & $>6<10$ & $40 \%$ \\
\hline 3 & $>11<15$ & $60 \%$ \\
\hline 4 & $>16<20$ & $80 \%$ \\
\hline 5 & $>21<25$ & $100 \%$ \\
\hline
\end{tabular}

\section{KESIMPULAN}

1. Sensor proximity yang digunakan untuk pendeteksian tangan pada penelitian ini mampu mendeteksi tangan dengan range jarak dari $3-12 \mathrm{~cm}$.

2. Sensor ultrasonik yang digunakan untuk pendeteksian persediaan pada kedua tangki ini dapat bekerja secara linieritas dan memiliki nilai sensitifitas terhadap perubahan volume sebesar 59,261 $\mu \mathrm{S} / \mathrm{cm}$ untuk sensor air dan 58,282 $\mu \mathrm{S} / \mathrm{cm}$ juga tingkat keakurasian pembacaan senor dengan jarak aktual sebesar 99,68\% dan 99,61\%.

3. LCD dapat menampilkan jumlah level monitoring sesuai dengan hasil pembacaan pada senor ultrasonik dalam bentuk persentase $0-100 \%$. 


\section{DAFTAR PUSTAKA}

[1] KEMENTRIAN KESEHATAN REPUBLIK INDONESIA. (n.d.). Gerakan PHBS Sebagai Langkah Awal Menuju Peningkatan Kualitas Kesehatan Masyarakat. Retrieved March 29, 2020, from http://promkes.kemkes.go.id/phbs

[2] World Health Organization. (n.d.). SAVE LIVES: Clean Your Hands 5 May 2020. Retrieved May 20, 2020, from https://www.who.int/infection-prevention/campaigns/cleanhands/5may2020/en/

[3] Kemenkes RI. (2020). Keputusan menteri kesehatan republik indonesia nomor hk.01.07/menkes/328/2020 tentang panduan pencegahan dan pengendalian. Keputusan Menteri Kesehatan Republik Indonesia Nomor Hk.01.07/Menkes/413/2020 Tentang Pedoman Pencegahan Dan Pengendalian Coronavirus Disease 2019 (Covid-19), 2019.

[4] Hafizur Rizki, W. (2015). Mikrokontroller ATmega8535 Dengan Menggunakan Sensor Fotodioda. Jurnal Fisika Unand, 4(2), 106-112.

[5] Hendri, H. (2018). Pembersih Tangan Otomatis Dilengkapi Air, Sabun, Handdryer Dan Lcd Menggunakan Sensor Infrared Berbasis Arduino. 8(1), 1-14. 